\section{Clip and snare lifting technique to assist cannulation of a papilla hidden behind a mucosal fold}

Endoscopic retrograde cholangiopancreatography (ERCP) is a technically complex endoscopic procedure with significant rates of severe complications $(0.8 \%)$ and mortality (0.02\%) [1]. Complication rates increase in those patients where cannulation is difficult, defined as a situation in which the operator using a standard technique fails to achieve cannulation within 5 minutes, makes five unsuccessful attempts, or two passages of the guidewire into the pancreas [2,3]. Features that are known to be associated with difficult, time-consuming, or impossible cannulations are failure to identify the papilla within the diverticulum, a floppy papilla on the edge of diverticula, and a papilla that is hidden by a mucosal fold ( Fig.1a) [4]. The latter situation can be particularly challenging and has few possible solutions [5].

We hereby describe the first two patients in which we used an endoclip and a snare to lift the mucosal fold and allow access to a hidden papilla. The first patient was a 70-year-old woman with a bile leak after hemihepatectomy. She had a flat papilla, underneath a floppy mucosal fold, that could not be cannulated. The second patient was a 55-year-old woman with a post-cholecystectomy bile leak. She had a papilla that was hidden behind a fold and had undergone two ERCPs and a precut sphincterotomy because of unsuccessful bile duct cannulation.

In both patients an endoclip (Resolution Clip; Boston Scientific Corporation, Natick, Massachusetts, USA) was placed on the fold. The duodenoscope was withdrawn and was then re-introduced with a biopsy forceps inside the working channel that was used to grasp a polypectomy snare (Sensation Short Throw, $13 \mathrm{~mm}$; Boston Scientific) so that this was introduced beside the scope. The snare loop was then tightened slightly around the shaft of the endoclip ( Fig.1 b) and the wire was pulled up through the mouth $(\bullet$ Fig. $1 \mathrm{c}$ ), which slightly altered the alignment of the papillary region, so allowing the opening of the papilla to be visualized ( $\bullet$ Fig. $1 \mathrm{~d}$ ) and successfully cannulated.

These are the first successful cases of clip and snare-assisted cannulation, a way of accessing the bile duct in otherwise apparently impossible conditions, by either pulling or pushing ( Fig.2) a snared clip that had been previously positioned on the mucosal fold that was hiding the papilla.

Endoscopy_UCTN_Code_TTT_1AR_2AB
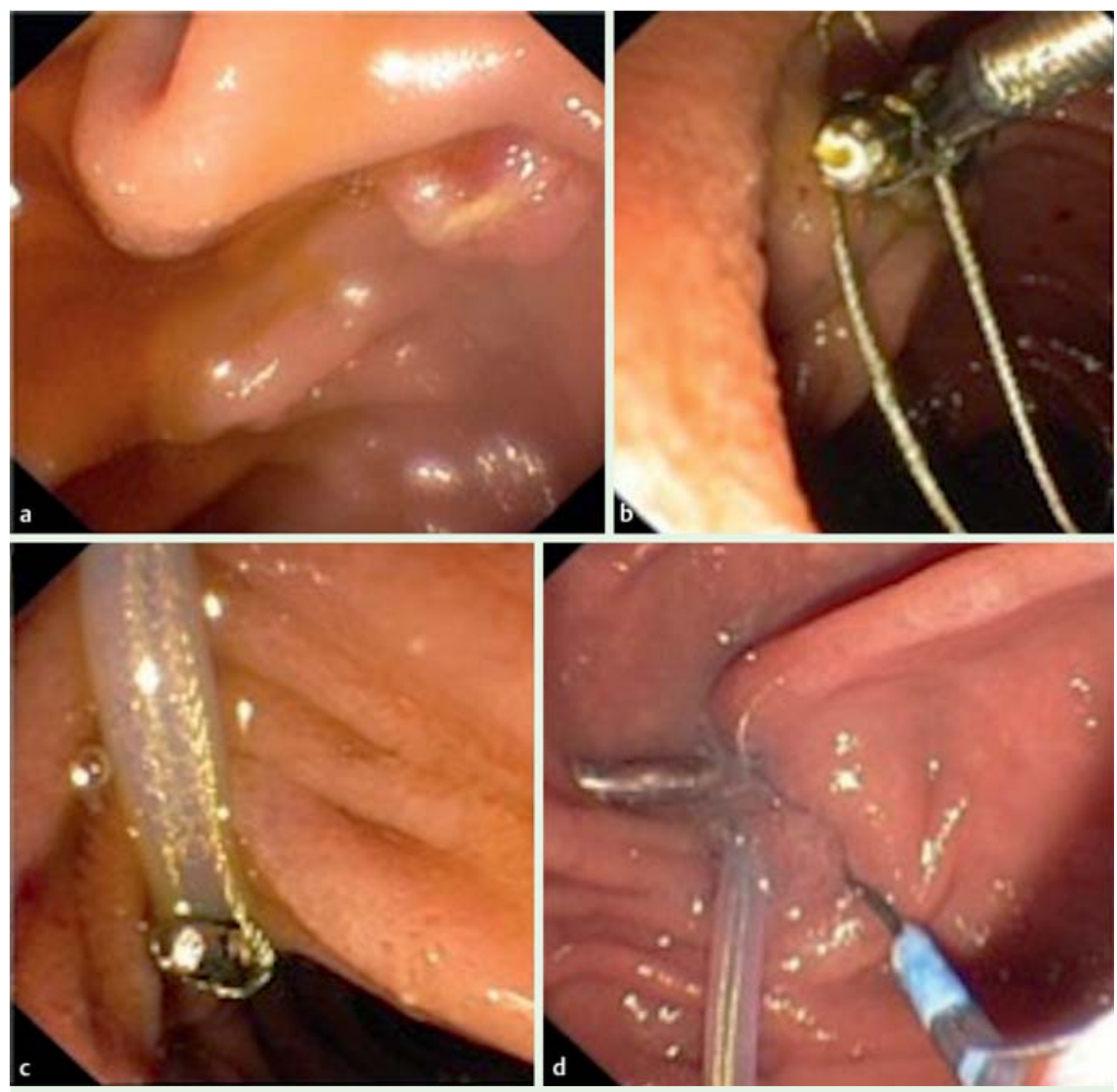

Fig. 1 Endoscopic views showing: a the mucosal fold with the papilla hidden behind it; $\mathbf{b}, \mathbf{c}$ the snare being tightened around the previously positioned endoscopic clip, and being pulled back; $\mathbf{d}$ the papilla, which is successfully visualized after use of a push-and-pull technique, subsequently allowing the common bile duct to be cannulated. 


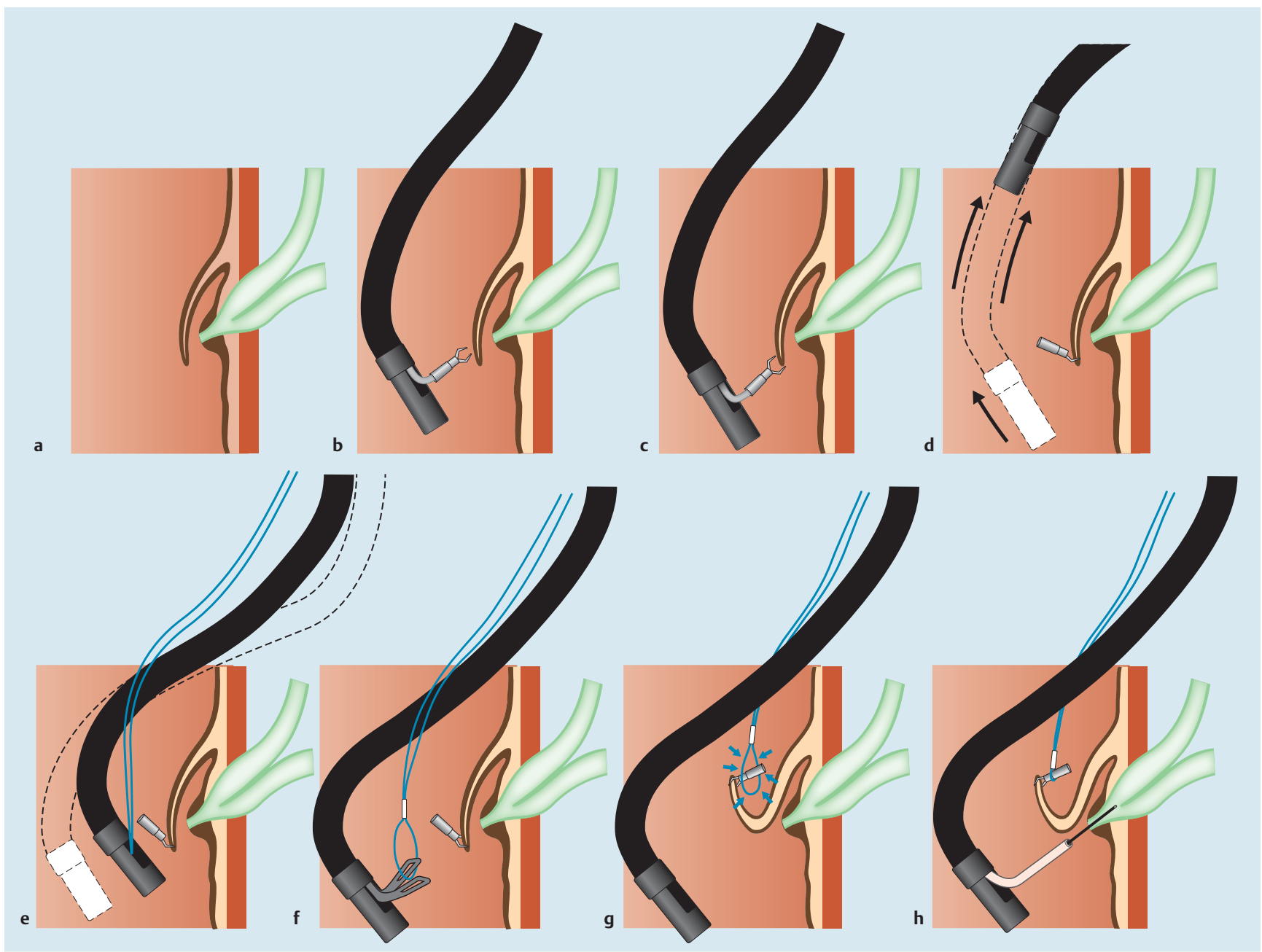

Fig. 2 Schematic showing the stages of the clip and snare-assisted cannulation process: a the papilla is not easily visualized as it is hidden behind a mucosal fold; $\mathbf{b}, \mathbf{c}$ an endoclip is placed on the fold; $\mathbf{d}$ the endoscope is withdrawn; $\mathbf{e}$ a snare grasped in a biopsy forceps is passed alongside the scope as it is re-inserted; $\mathbf{f}$ the snare loop is placed around the shaft of the clip; $\mathbf{g}$ the snare is pulled back lifting the fold away from the papilla; $\mathbf{h}$ the papilla can then be successfully cannulated.

Competing interests: None

\section{Roberto Valente ${ }^{1,2}$, Francisco Balda- que-Silva ${ }^{1}$, Antti Siiki ${ }^{3}$, Jeanne Lübbe ${ }^{4}$, Lars Enochson ${ }^{1}$, Matthias Lohr ${ }^{1}$, Urban Arnelo ${ }^{1}$}

${ }^{1}$ Pancreatic Surgery Unit, Department of Clinical Science, Intervention and Technology (CLINTEC), Karolinska Institute, Stockholm, Sweden

2 Digestive and Liver Disease Unit, Sant'Andrea Hospital, Sapienza University of Rome, Rome, Italy

3 Department of Gastroenterology and Alimentary Tract Surgery, Tampere University Hospital, Tampere, Finland

${ }^{4}$ Division of Surgery, Tygerberg Hospital and the University of Stellenbosch, Tygerberg, South Africa

\section{References}

1 Salminen P, Laine S, Gullichsen R. Severe and fatal complications after ERCP: analysis of 2555 procedures in a single experienced center. Surg Endosc 2008; 22: 1965 - 1970

2 Udd M, Kylänpää L, Halttunen J. Management of difficult bile duct cannulation in ERCP. World J Gastrointest Endosc 2010; 2: 97-103

3 Halttunen J, Meisner S, Aabakken L et al. Difficult cannulation as defined by a prospective study of the Scandinavian Association for Digestive Endoscopy (SADE) in 907 ERCPs. Scand J Gastroenterol 2014; 49: $752-758$

4 Tham TC, Kelly M. Association of periampullary duodenal diverticula with bile duct stones and with technical success of endoscopic retrograde cholangiopancreatography. Endoscopy 2004; 36: 1050-1053

5 Fujita N, Noda Y, Kobayashi G et al. ERCP for intradiverticular papilla: two-devices-inone-channel method. Endoscopic Retrograde Cholangiopancreatography. Gastrointest Endosc 1998; 48: 517-520
Bibliography

Dol http://dx.doi.org/

$10.1055 / \mathrm{s}-0034-1392923$

Endoscopy 2015; 47: E517-E518

(c) Georg Thieme Verlag KG

Stuttgart · New York

ISSN 0013-726X

\section{Corresponding author}

\section{Urban Arnelo, MD, PhD}

Department for Clinical Science, Intervention and Technology (CLINTEC) - Division of Surgery Karolinska Institute

Huddinge, K53

Stockholm S-14186

Sweden

Urban.Arnelo@ki.se 